\title{
Study on Contact Explosion Performance of Nuclear Containment
}

\author{
Qiang Xu', ${ }^{1,2}$ Xiangyu Cao' ${ }^{2}$ Jianyun Chen ${ }^{1,2}$, Jing $\mathrm{Li}^{2}$, Yang Cao \\ ${ }^{1}$ State Key Laboratory of Coastal and Offshore Engineering, Dalian University of Technology, Dalian, China \\ ${ }^{2}$ Faculty of Infrastructure Engineering, Dalian University of Technology, Dalian, China \\ Email: xuqiang528826@dlut.edu.cn
}

How to cite this paper: $\mathrm{Xu}, \mathrm{Q}$., Cao, X.Y. Chen, J.Y., Li, J. and Cao, Y. (2017) Study on Contact Explosion Performance of $\mathrm{Nu}$ clear Containment. Energy and Power Engineering, 9, 486-494.

https://doi.org/10.4236/epe.2017.94B054

Received: March 4, 2017

Accepted: March 30, 2017

Published: April 6, 2017

\begin{abstract}
Reinforced concrete (RC) shield building as the first external defense layer of AP1000 structure plays an important role in protection the population and environment when against the outer explosion. The strain rate effect of reinforced concrete was taken into consideration in the establishment of an AP1000 nuclear island structure-air-explosives fully coupled model by using the software AUTODYN. Object using damage mass as index, to infer the degree of damage. This paper studied the pressure evolution and damage mechanism. The analysis results provide valuable data on improving the anti-explosion capabilities in design based on the damage characteristics.
\end{abstract}

\section{Keywords}

AP1000 Nuclear Island, Contact Explosion, Damage Characteristic, Dynamic Responses

\section{Introduction}

Most studies on nuclear power plants subjected to contact explosion have put their interests in the reinforced concrete containment vessel. Many works have been done to the dynamic response of the reinforced concrete containment under internal explosion [1] [2] [3]. Other works have carried out numerical simulations on the damage mode under aircraft crash [4] [5]. However, researches about the damage mode and pressure evolution of shield building under contact explosion were few in the past years.

In this paper, the dynamic response of the AP1000 nuclear island under a contact explosion load at different initiation positions will be discussed. This paper also aims to find the most unfavorable position for contact explosion and provide valuable data on improving the anti-explosion capabilities in design 
based on the damage characteristics.

\subsection{Physical and Numerical Model}

The RC shield building is the first external defense layer of AP1000 structure to protect the containment vessel. The geometry of AP1000 model and boundary conditions are shown in Figure 1(a) and Figure 1(b). The CEL algorithm, based on the FSI approach, was used for numerically simulation. The concrete and the steel reinforcement were simulated by a Lagrangian mesh, while the TNT explosive and the air around the structure were simulated by an Eulerian mesh.

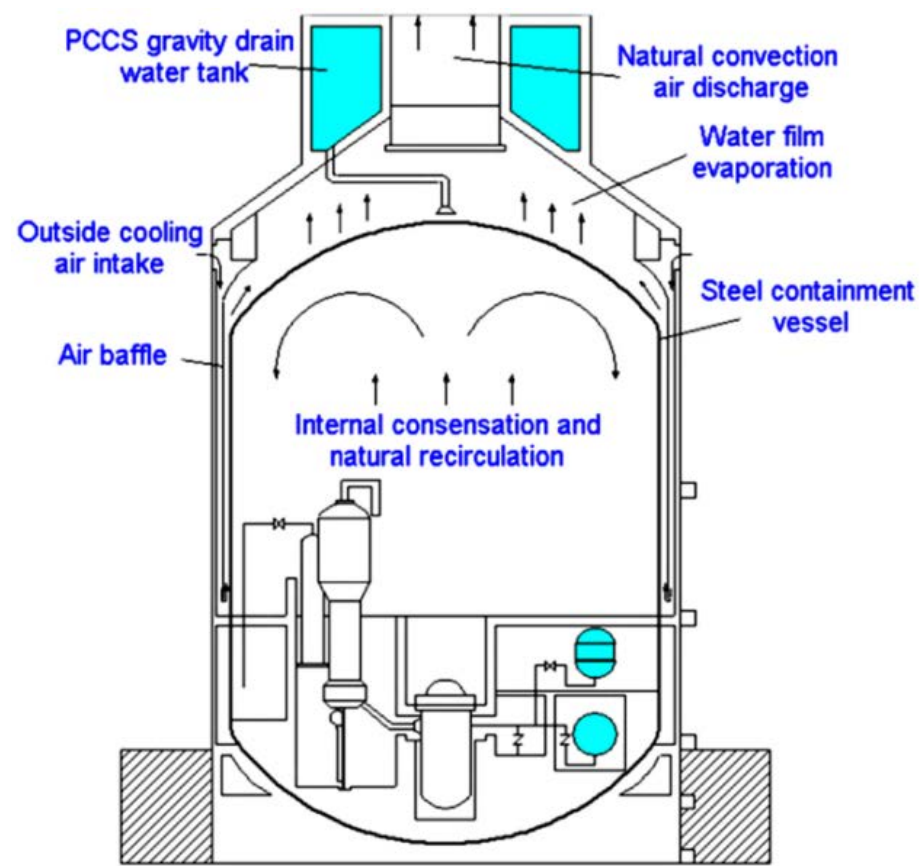

(a)

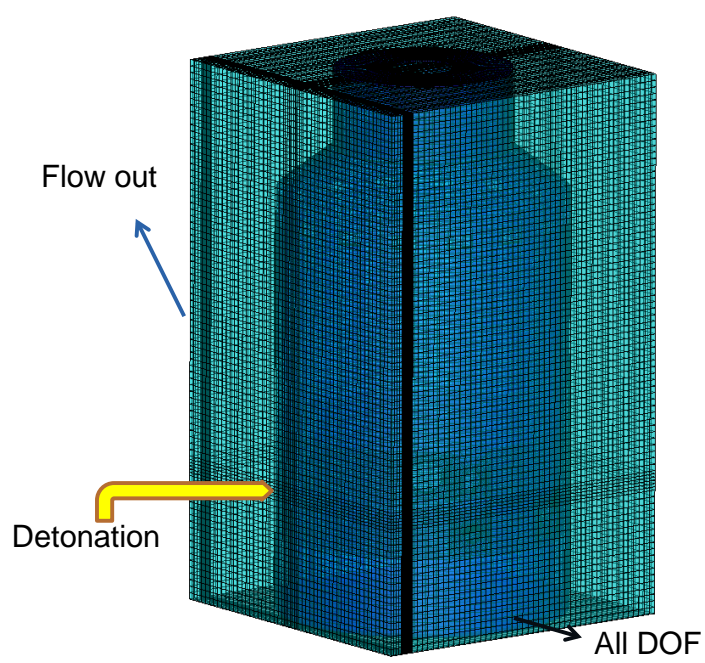

(b)

Figure 1. Model of an AP1000 shield building. (a) Geometry of the shield building. (b) Fully coupled numerical model and the boundary conditions. 


\subsection{Calculation Conditions}

Considering the randomness of the contact explosion positions, multiple initial detonation positions were selected for this study. In order to describe the calculation conditions directly, the name of each part of the nuclear island and the definition of the initial angle are shown in Figure 2. In the axial direction, five typical positions of the plant were selected as the axial conditions of the blasting point: I) the middle height of the orifice, II) $2 / 3$ height of the shied building, III) 5 meters below the air intake, IV) the middle height of wedge, and V) the middle height of the water tank. For each condition, the 12 monitored target points (P1-P12) were arranged in the axial direction, as shown in Figure 3.

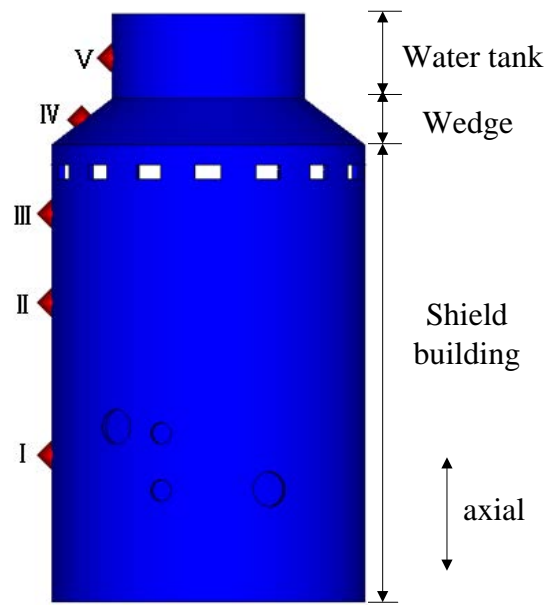

Figure 2. The arrangement of the burst spot

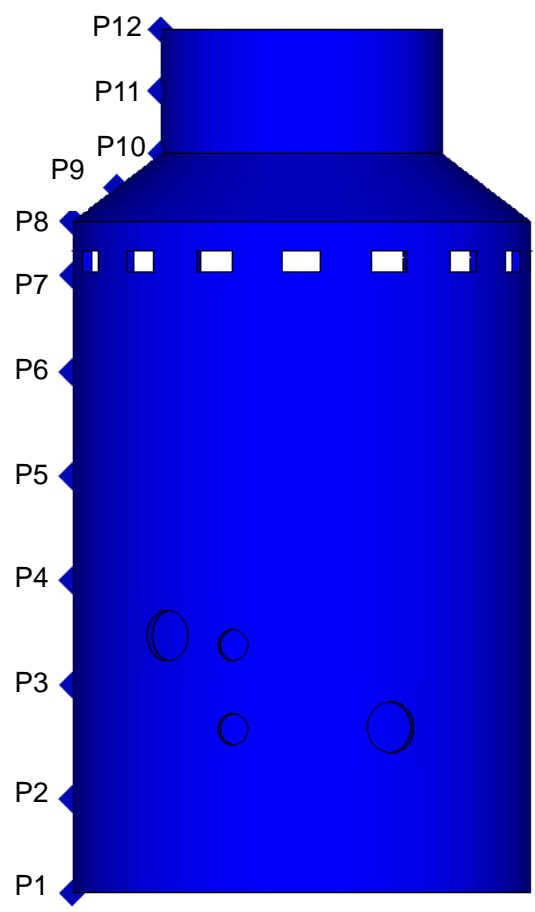

Figure 3. The arrangement of monitored target point. 


\subsection{Material Model}

Autodyncontains a variety of material models. In the numerical model, the Riedel-Hiermaier Thoma (RHT) concrete strength model is used to give a description of the dynamic response characteristics of concrete [6]. The reinforcement steel is represented by the Johnson and Cook material model. High explosives, such as TNT, are typically modeled using the Jones-Wilkins-Lee (JWL) expression of state (EOS), which represents the pressure generated by chemical energy in an explosion (Johnson GR et al., 1983). Air is modeled by an ideal gas EOS, which is one of the simplest forms of EOS. The numerical model used in this paper can reproduce the failure process of a reinforced concrete structure has proved in previous study.

\section{Dynamic Response Analysis of Shield Building}

\subsection{Analysis of Grid Convergence}

The mesh size has a great effect on the accuracy of numerical results. The results of nuclear island frequency on three different element sizes are shown in Table 1. The 1st natural frequency error of $500 \mathrm{~mm}$ and $800 \mathrm{~mm}$ compared to $300 \mathrm{~mm}$ are $1.6 \%$ and $1.1 \%$.

Therefore, it was finally decided to mesh the area around the explosive position, orifice and air intake with a mesh size of $300 \mathrm{~mm}$ and other areas with a size of $500 \mathrm{~mm}$. In this way, the calculation efficiency could be improved, and greater accuracy of the calculation could be achieved.

\subsection{Pressure Evolution Analysis}

Figure 4 shows the pressure wave evolution of condition I within 50ms. At $1 \mathrm{~ms}$, the explosive releases a large amount of energy in a very short time, and the positive peak pressure rise rapidly to $315.4 \mathrm{MPa}$, which exceeds the compressive strength of concrete. At $3 \mathrm{~ms}$, the positive peak pressure declines to $19.18 \mathrm{MPa}$ and the energy density per unit area of the structure decreases sharply. The maximum pressure is offset along the direction of the orifice. At $12 \mathrm{~ms}$, the positive peak pressure of the structure continue to decreases and shift to the orifice. At $30 \mathrm{~ms}$, the positive peak pressure is concentrated in the area of the air intake and the orifice beside the center of the explosion source.

\subsection{Damage Evolution Analysis}

Figure 5 shows the damage evolution of conditions I whthin $50 \mathrm{~ms}$. In order to explore the different degrees of damage, this paper takes the damage mass as the

Table 1. Nuclear island frequency for three different element sizes.

\begin{tabular}{cccc}
\hline Element size $(\mathrm{mm})$ & 1st Frequency $(\mathrm{Hz})$ & 2st Frequency $(\mathrm{Hz})$ & 3st Frequency $(\mathrm{Hz})$ \\
\hline 300 & 3.3169 & 3.3265 & 5.1410 \\
500 & 3.3666 & 3.3771 & 5.1918 \\
800 & 3.3720 & 3.3824 & 5.1848 \\
\hline
\end{tabular}




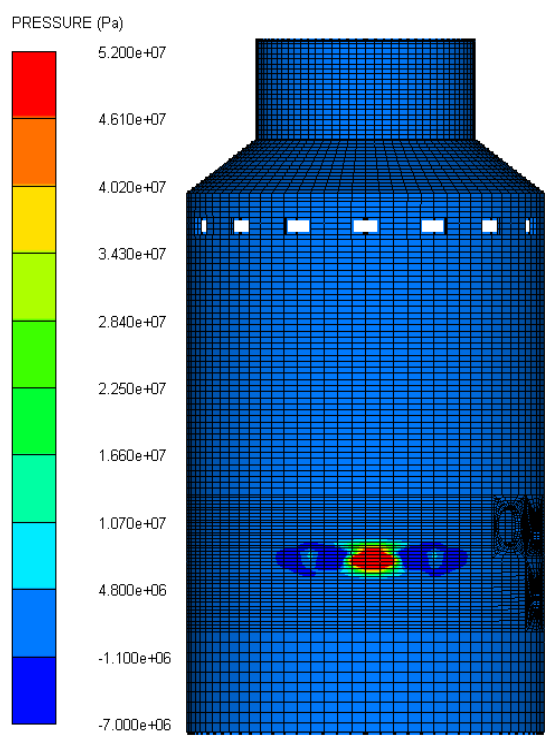

(a)

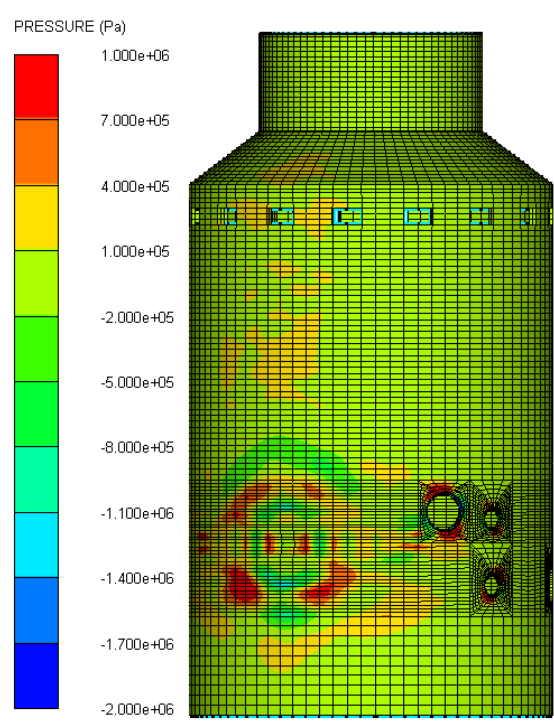

(d)

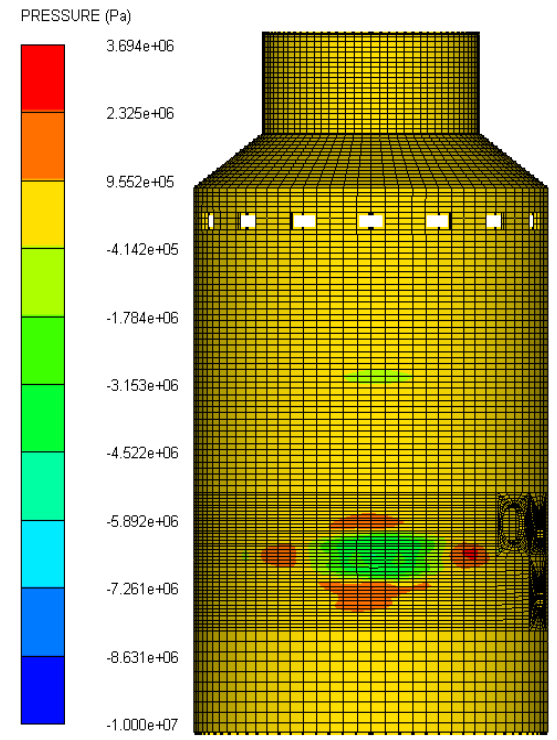

(b)

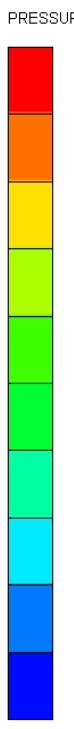

samexes

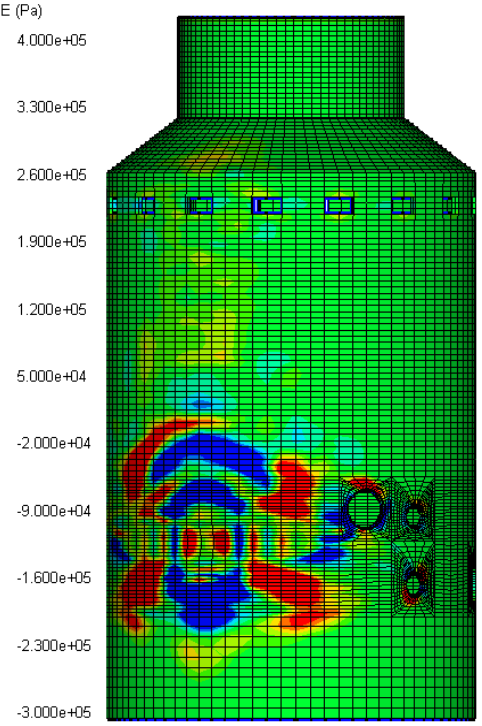

(e)

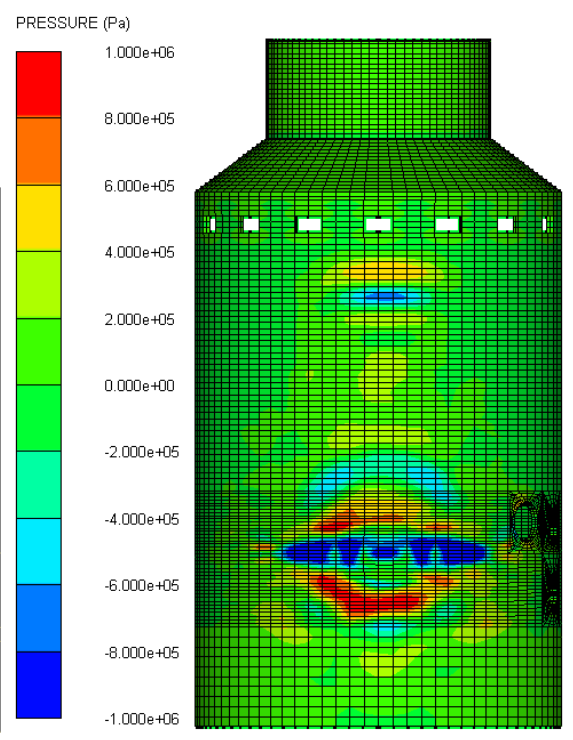

(c)

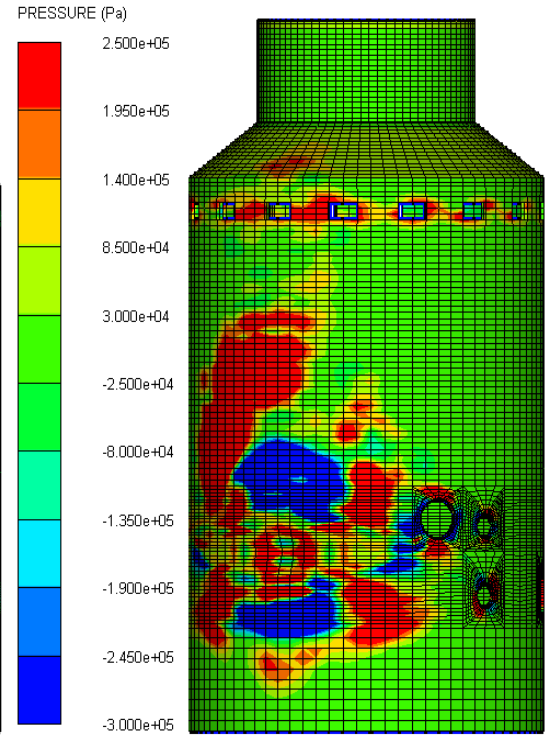

(f)

Figure 4. Condition I: Time sequences of pressure wave (Pa). (a) $1 \mathrm{~ms}$. (b) $5 \mathrm{~ms}$. (c) $9 \mathrm{~ms}$. (d) $20 \mathrm{~ms}$. (e) $30 \mathrm{~ms}$. (f) $50 \mathrm{~ms}$.

evaluation index. At $5 \mathrm{~ms}$, the explosive expend rapidly and formed a cavity filled with high-temperature and high-pressure gas. A elliptical crater was present on the center of the explosion source. The reinforced concrete lost carrying capacity, and the main damage area was formed. At this time, the damage is mainly induced by axial tension and compression. At $20 \mathrm{~ms}$, the stress wave continues to spread around the reinforced concrete, but the energy density of concrete per area decreases rapidly. A completely damaged structural area of the structure is formed. During $20 \mathrm{~ms}$ and $50 \mathrm{~ms}$, the completely damaged zone of the plant is no longer extended, and the decreased pressure continue to expand the area of the shallow damage zone. The maximum length of the fully damage area in the vertical and circumferential directions are $8.295 \mathrm{~m}$ and $12.32 \mathrm{~m}$, 
respectively. Figure 6 shows the history of fully damage mass of the shield building under condition I. It can be seen that the fully damage mass at $3 \mathrm{~ms}$ and $20 \mathrm{~ms}$ after the explosion occurred $88 \%$ and $98 \%$ of the stable, fully damage mass.

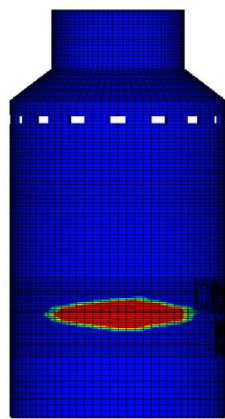

(a)

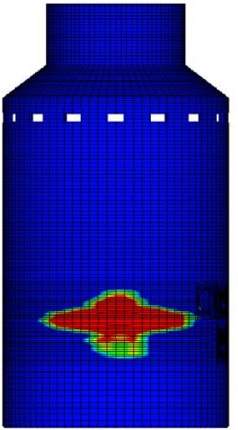

(d)

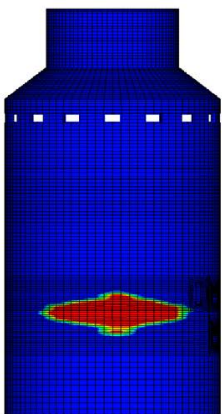

(b)

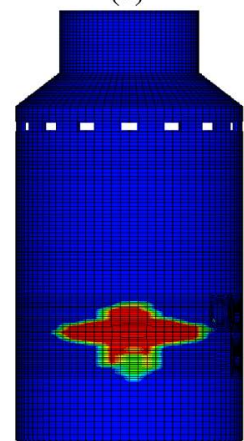

(e)

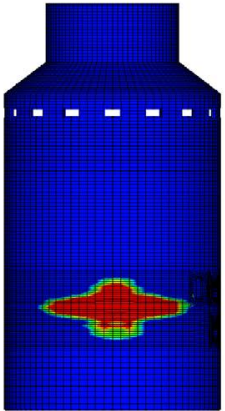

(c)

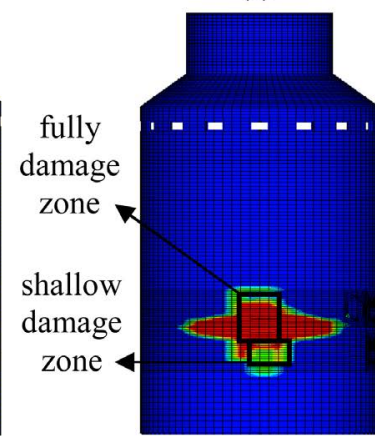

(f)

Figure 5. Condition I: Damage propagation process. (a) $5 \mathrm{~ms}$. (b) $10 \mathrm{~ms}$. (c) 20 ms. (d) $30 \mathrm{~ms}$. (e) $40 \mathrm{~ms}$. (f) $50 \mathrm{~ms}$.

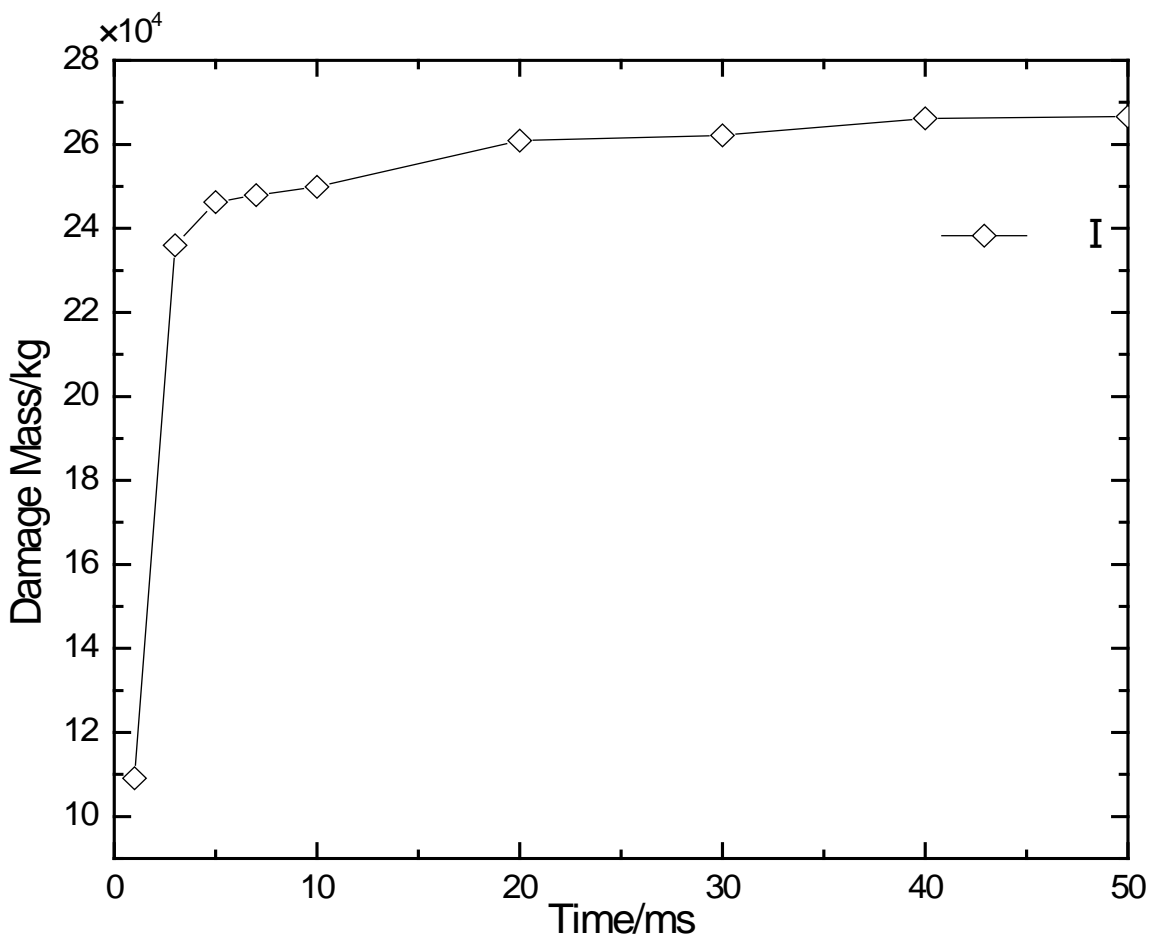

Figure 6. Condition 1: Damage mass-time curve. 


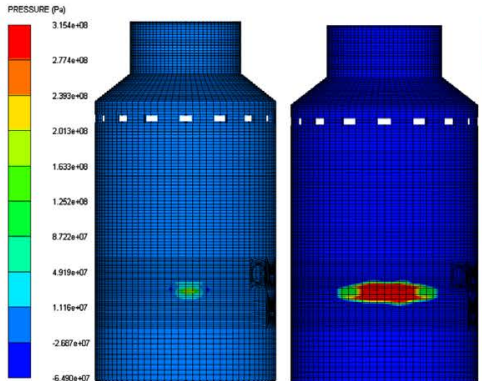

$1 \mathrm{~ms}$

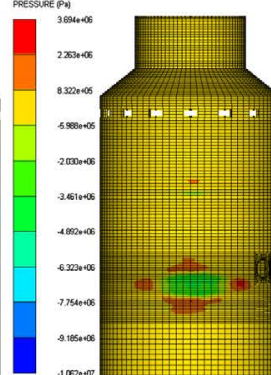

(1)

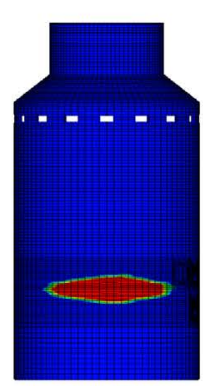

$5 \mathrm{~ms}$

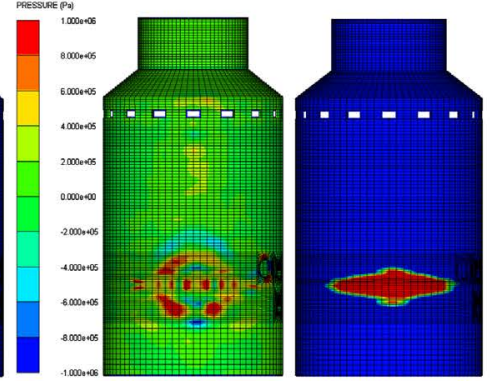

$10 \mathrm{~ms}$

Condition I

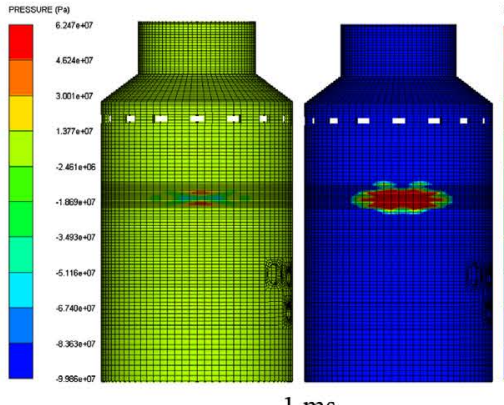

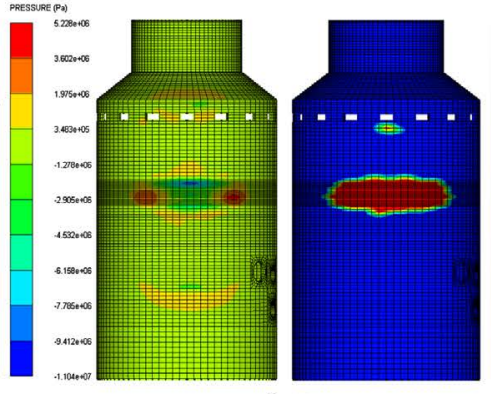

$5 \mathrm{~ms}$

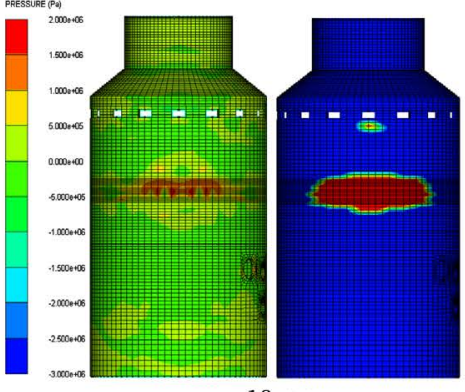

$10 \mathrm{~ms}$

Condition II

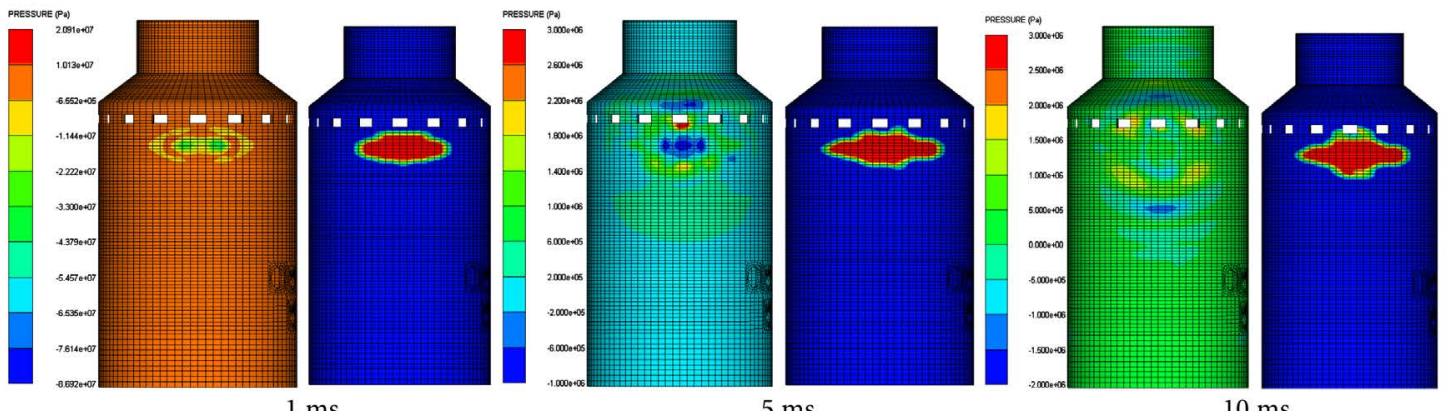

Condition III $1 \mathrm{~ms}$ $5 \mathrm{~ms}$ $10 \mathrm{~ms}$
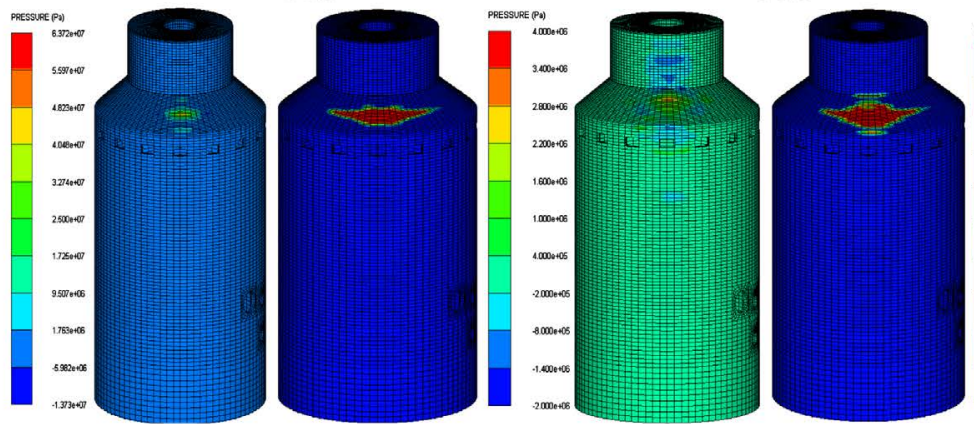

$5 \mathrm{~ms}$

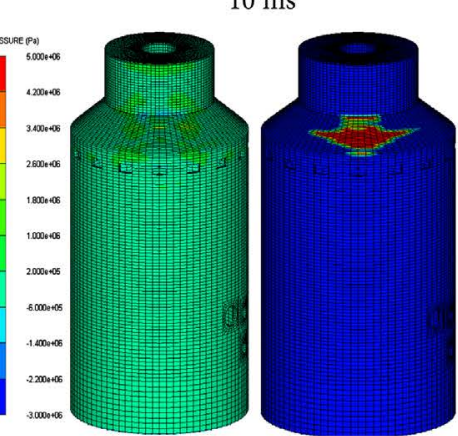

Condition IV

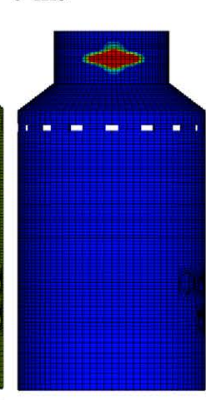

$5 \mathrm{~ms}$
$10 \mathrm{~ms}$

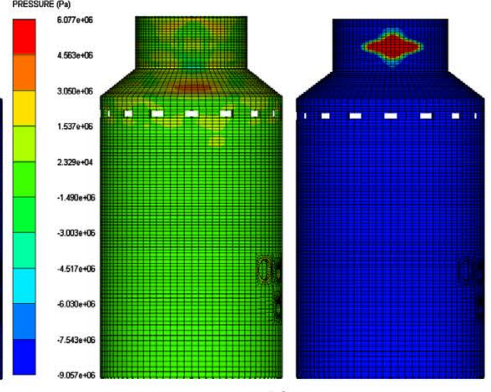

$10 \mathrm{~ms}$

Condition V $1 \mathrm{~ms}$

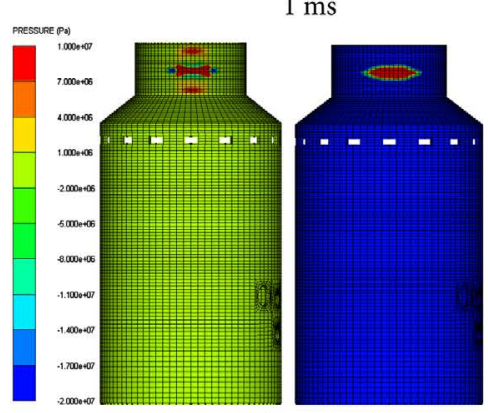

$1 \mathrm{~ms}$

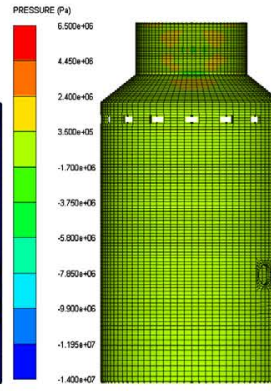

Figure 7. Comparision of pressure and damage cloud of condition I, II, III, IV, V. 


\subsection{Comparative Analysis}

This section focuses on the damage degree and mode with the same circumferential angle but different heights. According to the above conclusions, it's known that the damage degree is similar when the burst conditions are at the same height but have different circumferential angles. Therefore, this part uses condition I, II, III, IV, V as examples. Figure 7 shows the pressure and damage cloud of the above five conditions at $1 \mathrm{~ms}, 5 \mathrm{~ms}$ and $10 \mathrm{~ms}$.

When $\mathrm{t}=1 \mathrm{~ms}$, the pressure wave is concentrated in the explosion source region, and the pressure value is symmetrical to the horizontal axis for each condition. The crater's shape is an ellipse with the major axis in circumference, as previously explained. When $t=5 \mathrm{~m}$, the pressure waves of condition I and IV are symmetrical with the horizontal direction, and the pressure wave of condition II is no longer symmetrical. The positive pressure amplitude of condition III appears in the area of the orifice near the explosion source, and the center of explosion source is under negative pressure. The stress amplitude of condition $\mathrm{V}$ appears in the center of explosion and the area of a 45-degree angle to the horizontal direction, presenting an obvious shear failure mode. When $\mathrm{t}=10 \mathrm{~ms}$, the damage zone of condition $\mathrm{V}$ continues to expand, and the crack extended along the axial direction. The reason is that the reflected pressure waves propagate to the upper and bottom boundary of the water tank, which are superimposed in the axial direction to generate secondary damage.

Consequently, our results indicate that we should pay more attention to improving the longitudinal reinforcement in the parts of the shield building and the wedge (as shown in Figure 2). In the parts of the water tank, the longitudinal reinforcement and the circumferential reinforcement should be paid the same attention.

\section{Conclusion}

In this paper, we mainly focus on the pressure evolution processes and damage modes under contact explosion at five typical detonation positions. It' clearly that the degree of damage of the contact explosion occurring in the shield building is larger than that experienced by the wedge and water tank, which indicates that the most unfavorable position under a contact explosion is located between the orifice and air intake. Through the analysis of damage characteristics more attention to improving longitudinal reinforcement in the parts of shield building and the wedge should be paid. In the parts of the water tank, longitudinal and circumferential reinforcement should be paid the same attention.

\section{Acknowledgements}

The research described in this paper was financially supported by Educational Commission of Liaoning Province of China (No. LZ2015022), the State Key Development Program for Basic Research of China (No. 2013CB035905).

\section{References}

[1] Zheng, J., Hu, Y., Ma, L. and Du, Y. (2015) Delamination Failure of Composite 
Containment Vessels Subjected to Internal Blast Loading. Composite Structures, 130, 29-36. https://doi.org/10.1016/j.compstruct.2015.04.013

[2] Dong, Q., Li, Q.M. and Zheng, J.Y. (2010) Further Study on Strain Growth in Spherical Containment Vessels Subjected to Internal Blast Loading. International Journal of Impact Engineering, 37, 196-206. https://doi.org/10.1016/j.ijimpeng.2009.09.001

[3] Chen, X., Wang, F.Y. and Wu, Y.P. (2012) Numerical Simulation of Dynamical Responses of Explosion Vessel to Impact Load. Pressure Vessel Technology, 3, 5.

[4] Frano, R.L. and Forasassi, G. (2011) Preliminary Evaluation of Aircraft Impact on a Near Term Nuclear Power Plant. Nuclear Engineering and Design, 241, 5245-5250. https://doi.org/10.1016/j.nucengdes.2011.08.079

[5] Riedel, W., Thoma, K. and Hiermaier, S. (1999) Penetration of Reinforced Concrete by BETA-B-500 Numerical Analysis Using a New Macroscopic Concrete Model for Hydrocodes. Proc 9, ISIEMS, Berlin, 315-322.

[6] Johnson, G.R. and Cook, W.H. (1983) A Constitutive Model and Data for Metals Subjected to Large Strains, High Strain Rates and High Temperatures. Proceedings of the Seventh International Symposium on Ballistics, The Hague, 541-548.

\section{Submit or recommend next manuscript to SCIRP and we will provide best service for you:}

Accepting pre-submission inquiries through Email, Facebook, LinkedIn, Twitter, etc. A wide selection of journals (inclusive of 9 subjects, more than 200 journals) Providing 24-hour high-quality service User-friendly online submission system Fair and swift peer-review system Efficient typesetting and proofreading procedure Display of the result of downloads and visits, as well as the number of cited articles Maximum dissemination of your research work

Submit your manuscript at: http://papersubmission.scirp.org/

Or contact epe@scirp.org 